\title{
Dimensional stability of alginate molds scanned at different storage times
}

\author{
Gabriel D. Daneu, Juliana de B. Vasconcelos, Paula V.P. Oltramari, Marcio R. de Almeida, \\ Ricardo D. Guiraldo, Thais M. F. Fernandes
}

Universidade Pitágoras Unopar (UNOPAR), Faculdade de Odontologia, Departamento de Ortodontia, Londrina, Brasil.

\begin{abstract}
The aim of this study was to evaluate the precision and accuracy of molds made with four commercial brands of alginate scanned at different times using digital model analysis. Eighty molds of a standard Typodont were made using 4 types of alginate (CCC: Cavex Color Change; IA: Identic Alginate; HY5: Hydrogum 5 and JP: Jeltrate Plus). The molds were scanned at four times: immediately (T1), $24 \mathrm{~h}$ (T2), $72 \mathrm{~h}$ (T3) and 120h (T4) after molding. Measurements were taken in three dimensions: anteroposterior, transverse and vertical. Significant differences in dimensional changes were noted between the materials over time $(p<0.05)$. Anteroposterior dimensional variation was noted between times, especially for IA and JP. For transverse
\end{abstract}

and vertical variables, a difference was found between the groups, especially at $24 h, 72 h$ and $120 h$. CCC presented significant dimensional shrinkage only at T120 (transverse). $I A$ and JP presented larger dimensional distortions in the vertical measurements. The molding materials used were not dimensionally stable when evaluated after 120 hours of molding. However, such evidence suggests that alginates with longer storage time, such as Cavex Color Change, are more accurate than conventional alginates.

Received: September 2020; Accepted: October 2020

Keywords: dental impression materials - dental models - three dimensional imaging.

\section{Estabilidade dimensional de moldes de alginato digitalizados em diferentes tempos de armazenamento}

\begin{abstract}
RESUMO
O objetivo do presente estudo foi avaliar a precisão e acurácia por meio de análise de modelos digitais de moldes digitalizados obtidos com quatro marcas comerciais de alginato em diferentes tempos. Oitenta moldes de um Typodont padrão foram obtidos utilizando 4 tipos de alginato (CCC: Cavex Color Change; IA: Identic Alginate; HY5: Hydrogum 5 e JP: Jeltrate Plus). Os moldes foram escaneados em quatro tempos: imediatamente (T1), $24 \mathrm{~h}$ (T2), $72 \mathrm{~h}$ (T3) e $120 \mathrm{~h}$ (T4) após a moldagem. As medidas foram feitas em três dimensões: ântero-posterior, transversal e vertical. Diferenças significativas nas mudanças dimensionais foram observadas entre os materiais ao longo do tempo $(p<0,05)$. Variação dimensional ântero-posterior foi ob-
\end{abstract}

\section{INTRODUCTION}

Digital technology is spreading throughout all sectors of society. There has been noticeable modernization over the years, especially in diagnostic procedures, in which digital virtualization techniques of dental models are increasingly available, providing quality servada entre os tempos, principalmente para IA e JP. Para as variáveis transversal e vertical houve diferença entre os grupos, principalmente em $24 \mathrm{~h}, 72 \mathrm{~h}$ e $120 \mathrm{~h}$. CCC apresentou contração dimensional significativa apenas em T120 (transversal). IA e JP apresentaram maiores distorções dimensionais na vertical. Os materiais de moldagem utilizados não foram dimensionalmente estáveis quando avaliados após 120 horas de moldagem. No entanto, tais evidências sugerem que os alginatos com maior tempo de armazenamento, como Cavex Color Change, são mais precisos do que os alginatos convencionais.

Palavras-chave: materiais para moldagem odontológica modelos dentários - imageamento tridimensional.

3D images and fully computerized orthodontic documentation ${ }^{1}$.

Plaster models, though considered standard and being widely used by orthodontists for diagnosis and treatment planning, have disadvantages compared to 
digital models, which appear to be a good option to replace traditional methods. The speed in obtaining data and measurements, easy storage and access to information, make digital models an alternative to plaster models ${ }^{2}$. This convenience of archiving data on the computer enables data exchange information with colleagues from other centers via the web, contributing to diagnosis, especially when case planning requires an integrated multidisciplinary approach $^{3,4}$.

One of the methods for producing a digital model is scanning moldings and plaster models. Scanners collect data on shape and appearance, transforming it into a 3D scanned file, in which measurements are obtained with the aid of specific software ${ }^{5}$. Currently, $3 \mathrm{D}$ imaging is obtained by directly scanning the alginate or silicone mold. These molds and models can be used for virtual setup, aesthetic aligners and indirect bonding trays ${ }^{6}$. Another alternative for obtaining digital models is through intraoral scanning, which reduces image acquisition time and eliminates the need for molding. On the other hand, this is a new technology, with high cost, making it difficult to use and it is a very sensitive technique, requiring high operator calibration in order to avoid errors in image obtention ${ }^{7}$. In addition, studies are needed to evaluate the precision and accuracy of the measurements obtained by this technique ${ }^{8}$.

The accuracy of digital models is closely linked to the printing process, and molding failures can compromise procedures. Studies show that alginate prints undergo dimensional changes related to time and temperature ${ }^{3,4,6,9}$. Due to the recognition that the main limitation of alginate is the volumetric change in the mold after it is removed from the mouth, materials with better stability characteristics and longer handling time are being produced ${ }^{10}$. The aim of this study was to evaluate the precision and accuracy of dimensional stability of four alginate types scanned at different times.

\section{MATERIALS AND METHODS}

Eighty upper arch molds were obtained from a standard Typodont with four different alginate materials: CCC: Cavex Color Change (Cavex Holland BV, Haarlem, The Netherlands); IA: Identic Alginate (Dux Dental, Oxnard, Calif); HY5: Hydrogum 5 (Zhermack, Badia Polesine, RO, Italy) and JP: Jeltrate Plus (Dentsply Caulk, Milford, DE, USA). After the molding procedure, the trays were placed on the R700 ${ }^{\mathrm{TM}}$ scanner (3Shape, Copenhagen, Denmark) for their scanning process and digital model production. Scanning was performed at 4 time intervals: immediately (T1), 24 $\mathrm{h}$ (T2), $72 \mathrm{~h}$ (T3) and $120 \mathrm{~h}$ (T4) after molding. For each material, 5 molds were produced at each time interval, generating 5 digital models per material, and 80 models altogether. The Typodont upper arch was also scanned and it served as the gold standard for evaluations (OrthoAnalyzer, 3Shape, Copenhagen, Denmark).

\section{Obtaining digital models}

Molding materials were handled according to manufacturers' instructions in an environment with controlled temperature and relative humidity $(23 \pm 2$ ${ }^{\circ} \mathrm{C}$ and $50 \pm 10 \%$ ) to minimize factors that could cause dimensional change. After manipulation, it was placed over the entire inner part of the tray that was later seated over the upper Typodont arch. All molding steps were performed by a single operator. Immediately after obtaining the molds, they were scanned by a R $700^{\mathrm{TM}}$ scanner (3Shape, Copenhagen, Denmark) generating the digital models (Fig. 1). The molds which would be stored and scanned after 24, 72 and 120 hours were placed in a humidifier with $100 \%$ relative humidity at room temperature $\left(23^{\circ} \mathrm{C} \text { to } 25^{\circ} \mathrm{C}\right)^{11,12}$.

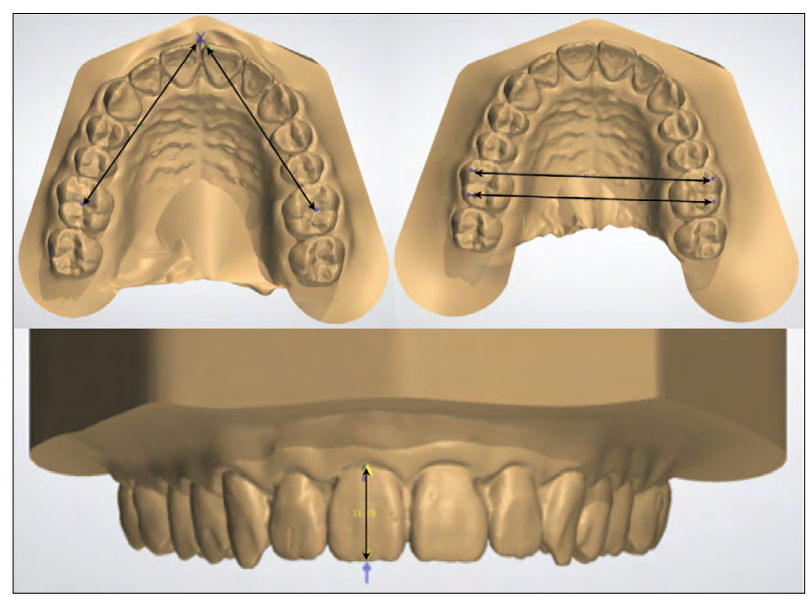

Fig. 1: Measurements performed: anteroposterior distance, transverse distance and vertical distance

\section{Evaluation of digital models}

Evaluations were performed by a calibrated evaluator in OrthoAnalyzer software (3Shape, Copenhagen, Denmark). The following measurements were recorded: anteroposterior distance, transverse distance and vertical distance (Fig. 1). 
- Anteroposterior distance: the models were measured in occlusal view from the occlusal-central point of the right first molar to the incisal mesial angle of the ipsilateral central incisor. The same measurement was performed from the first molar on the opposite side to the respective central incisor, and then the two measurements were divided by 2.4

- Transverse distance: reference points were established for the first molar buccal cusp tips (right and left). The distance between these points determined the transverse distance.

- Vertical distance: The vertical distance from the right central upper incisor was measured straight from the center of the incisal edge to the gingival margin ${ }^{4,13}$.

\section{Statistical analysis}

To verify the examiner's calibration, 30 days after the first evaluation, the measurements of $30 \%$ of the sample were repeated, totaling 384 measurements performed on 24 randomly selected digital models. Errors were evaluated by Intraclass Correlation Coefficient (ICC) and Bland-Altman. Statistical analysis was performed using Statistical Package for Social Sciences version 20.0 and Minitab 17.0, with a $95 \%$ confidence interval and a significance level of $5 \%(p<0.05)$ for all tests. One-way analysis of variance (ANOVA) was used to compare groups and times for different outcome variables. Subsequently, factorial ANOVA (Two-way ANOVA, Post-Test: Bonferroni) was used to identify the influence of each of these factors on the model, and to evaluate any possible interaction between them.

\section{RESULTS}

Table 1 presents the results for intra-examiner error. The ICC ranged from 0.79 to 1.0 , showing excellent agreement and reliability, and the Bland-Altman, with very little variation in the upper ( 0.01 to 0.20$)$ and lower (0.00 to 0.06) limits (Table 1). These results demonstrate that all variables studied were accurate and consistent, certifying the examiner's calibration.

The mean values of all measurements (different times and materials) are shown in Table 2. For anteroposterior distance, IA and JP presented a significant decrease at T120, while for HY5 this decrease was observed at T24 and T72. For transverse distance, the largest discrepancy was observed in HY5 and JP from T0 to T120. In the vertical dimension (Table 2), IA and JP showed significant differences at T120. At T24, CCC and HY5 obtained higher values than IA and JP. Moreover, at T120, IA and JP presented discrepant average values (10.92 and 10.86, respectively), with p 0.009*. Figs. 2 and 3 explain the interaction between groups in relation to APD and TD, respectively, at different times. The mean difference between the molds obtained from the different materials and the measurements at T0 and T120 from the Typodont (gold standard) are shown in Table 3. A slight reduction of all measurements was observed, with exception of IA for transverse distance, when compared to the gold standard. The material with the greatest discrepancy was JP $(-3.46 \%)$, followed by IA $(-3.02 \%)$, CCC $(-1.6 \%)$ and HY5 $(-1.42 \%)$ at T120 for vertical distance.

\section{DISCUSSION}

Alginate is an irreversible hydrocolloid ${ }^{11}$ that provides sufficiently detailed reproduction to make it suitable for routine use in dentistry, such as for obtaining diagnostic and working models for therapeutic appliances ${ }^{14}$. Despite its frequent use, concerns about its performance include dimensional instability when plaster casting is delayed, and inability to produce accurate molds upon re-casting. It is common for the dimensional stability of irreversible hydrocolloids to decrease with increasing storage time ${ }^{1}$ due to the gain or loss of water from the mold and the resulting dimensional changes. These can be minimized by immediate plaster filling ${ }^{11,12}$. In this study, four types of alginate were used: Cavex Color Change, Identic Alginate, Hydrogum 5 and Jeltrate Plus. The first three are irreversible hydrocolloids, which their manufacturers ensure will provide satisfactory results if the mold is filled with plaster within 5 days. Jeltrate Plus, which recommends only a few hours' storage, preferably in a humidifier, was used to compare the accuracy and dimensional accuracy of the models manufactured with these materials. When anteroposterior distance was evaluated in IA and JP, there was a decrease in the mean values at T120, whereas for HY5 the highest decrease was observed at T72. Higher values for JP were only observed at T72. Although a previous study ${ }^{9}$ showed no significant differences when evaluating Jeltrate Plus within 5 days, a different methodology was 
Table 1. Mean, standard deviation (SD) and difference from the first and second evaluation (millimeters). Intraclass Correlation Coefficient (ICC) and Bland-Altman

\begin{tabular}{|c|c|c|c|c|c|c|c|c|}
\hline \multirow{2}{*}{$\begin{array}{c}\text { Variables } \\
(\mathrm{mm})\end{array}$} & \multicolumn{2}{|c|}{ 1st Evaluation } & \multicolumn{2}{|c|}{ 2nd Evaluation } & \multirow{2}{*}{ Diff. } & \multirow{2}{*}{ ICC } & \multicolumn{2}{|c|}{ Bland-Altman } \\
\hline & Mean & SD & Mean & SD & & & Upper & Lower \\
\hline Anteroposterior Distance & 40.72 & 0.46 & 40.71 & 0.46 & -0.01 & 1.00 & 0.08 & 0.02 \\
\hline Transverse distance & 53.87 & 0.16 & 53.87 & 0.15 & 0 & 0.79 & 0.19 & 0.04 \\
\hline Vertical Distance & 11.09 & 0.16 & 11.06 & 0.13 & -0.03 & 0.81 & 0.20 & 0.06 \\
\hline
\end{tabular}

Table 2. Comparison of mean values of DAP, DT and DV between the different times and impression materials (Anova, Post-Test: Bonferroni) and multiple comparisons (two-way ANOVA).

\begin{tabular}{|c|c|c|c|c|c|c|c|c|c|c|}
\hline & \multicolumn{2}{|c|}{$\begin{array}{c}\text { T0 } \\
(n=5)\end{array}$} & \multicolumn{2}{|c|}{$\begin{array}{c}\text { T24 } \\
(n=5)\end{array}$} & \multicolumn{2}{|c|}{$\begin{array}{c}T 72 \\
(n=5)\end{array}$} & \multicolumn{2}{|c|}{$\begin{array}{l}T 120 \\
(n=5)\end{array}$} & \multirow[b]{2}{*}{$\begin{array}{c}\text { Difference } \\
\text { (time) }\end{array}$} & \\
\hline & Mean & SD & Mean & SD & Mean & SD & Mean & SD & & \\
\hline \multicolumn{11}{|c|}{ Anteroposterior Distance } \\
\hline CCC & 40.67 & 0.24 & 40.68 & 0.05 & $40.74 \mathrm{~A}$ & 0.07 & 40.74 & 0.07 & 0.064 & \\
\hline IA & 40.70 & 0.09 & 40.60 & 0.17 & $40.70 \mathrm{~A}$ & 0.03 & 40.38 & 0.14 & $0.0001^{*}$ & $\begin{array}{r}\text { T0 } \times \text { T72 } \\
\text { T0 } \times \text { T120 }\end{array}$ \\
\hline HY5 & 40.77 & 0.04 & 40.57 & 0.06 & $40.53 A$ & 0.06 & 40.66 & 0.12 & $0.004^{*}$ & $\begin{array}{l}\text { T0 } \times \text { T24 } \\
\text { T0x T72 }\end{array}$ \\
\hline \multirow[t]{2}{*}{ JP } & 40.80 & 0.08 & 40.78 & 0.30 & $41.50 \mathrm{~B}$ & 0.68 & 40.28 & 0.12 & $0.004^{*}$ & $\begin{array}{c}\text { T0XT72 } \\
\text { T0XT120 }\end{array}$ \\
\hline & \multicolumn{2}{|c|}{0.459} & \multicolumn{2}{|c|}{0.300} & \multicolumn{2}{|c|}{$0.002^{*}$} & \multicolumn{2}{|c|}{$0.001^{*}$} & & \\
\hline \multicolumn{11}{|c|}{ Transverse distance } \\
\hline CCC & 54.04 & 0.10 & $54.07 \mathrm{~A}$ & 0.03 & $54.00 \mathrm{~A}$ & 0.06 & 53.71 & 0.06 & $0.0001^{*}$ & T0 $\times$ T120 \\
\hline IA & 54.12 & 0.08 & 53.91A.B & 0.17 & $53.79 B$ & 0.03 & 53.83 & 0.09 & $0.0001^{*}$ & $\begin{array}{c}\text { T0xT24 } \\
\text { T0 x T72 } \\
\text { T0 x T120 }\end{array}$ \\
\hline HY5 & 54.00 & 0.02 & 53.96A.B & 0.06 & 53.87B & 0.02 & 53.61 & 0.08 & $0.0001^{*}$ & $\begin{array}{c}\text { T0 } \times \text { T72 } \\
\text { T0 } \times \text { T120 }\end{array}$ \\
\hline \multirow[t]{2}{*}{ JP } & 54.00 & 0.02 & 53.90B.C & 0.04 & $53.82 B$ & 0.16 & 53.57 & 0.072 & $0.0001^{*}$ & $\begin{array}{c}\text { T0 x T72 } \\
\text { T0 x T120 }\end{array}$ \\
\hline & \multicolumn{2}{|c|}{0.542} & \multicolumn{2}{|c|}{$0.035^{\star}$} & \multicolumn{2}{|c|}{$0.006^{\star}$} & \multicolumn{2}{|c|}{$0.0001^{*}$} & & \\
\hline \multicolumn{11}{|c|}{ Vertical Distance } \\
\hline $\mathrm{CcC}$ & 11.08 & 0.17 & $11.25 \mathrm{~A}$ & 0.04 & $11.13 \mathrm{~A}$ & 0.09 & $11.07 \mathrm{~A}$ & 0.09 & 0.173 & \\
\hline IA & 11.22 & 0.05 & 11.03B.C & 0.05 & $11.17 \mathrm{~A}$ & 0.06 & $10.92 B$ & 0.14 & $0.0001^{*}$ & T0 $\times$ T120 \\
\hline HY5 & 11.20 & 0.06 & 11.16A.C & 0.07 & 11.19A & 0.03 & $11.09 \mathrm{~A}$ & 0.07 & $0.0001^{*}$ & T0 $\times$ T120 \\
\hline \multirow[t]{2}{*}{ JP } & 11.16 & 0.07 & $10.98 \mathrm{~B}$ & 0.08 & 10.97B & 0.09 & $10.86 \mathrm{~B}$ & 0.12 & $0.0001^{*}$ & T0 $\times$ T120 \\
\hline & \multicolumn{2}{|c|}{0.172} & \multicolumn{2}{|c|}{$0.000^{*}$} & \multicolumn{2}{|c|}{$0.001^{*}$} & \multicolumn{2}{|c|}{$0.009^{*}$} & & \\
\hline
\end{tabular}

used, which did not involve digital molds. Mold shrinkage was observed between T0 and T24 in IA and HY5, and an increase in anteroposterior distance was recorded for JP between T24 and T72. All of these changes were also found in a previous study ${ }^{4}$, which stated that some materials are stable only when analyzed immediately and noted significant contraction of traditional alginates within 72 hours and within one week. Between T0 and T120, IA and JP presented higher contraction values, following the same explanations as in previous studies ${ }^{14,15}$, which suggested that traditional alginates tend to show greater distortions than alginates with extended filling period over time.

For all transverse measurements and vertical distances, there was a difference between groups, especially at $24 \mathrm{~h}, 72 \mathrm{~h}$ and $120 \mathrm{~h}$. For TD, there was a decrease in IA, HY5 and JP after 72h and $120 \mathrm{~h}$. CCC was the most stable, with a significant decrease only after $120 \mathrm{~h}$. A previous study ${ }^{16}$ analyzing Cavex 


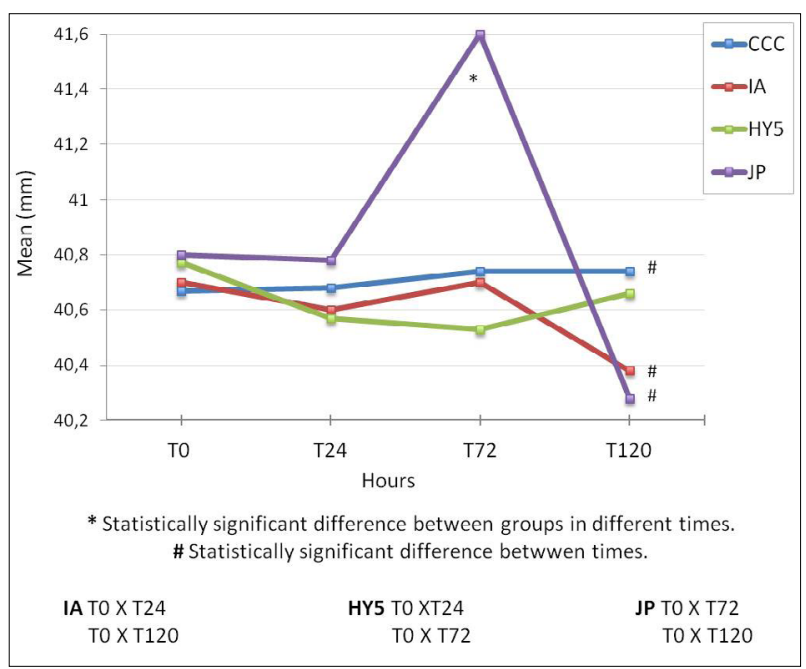

Fig. 2: Anteroposterior distance interaction graph

Color Change dimensions for four days found a greater contraction for TD1 from the fourth day. In contrast, Guiraldo et $\mathrm{al}^{12}$ concluded that Cavex Color Change did not show significant changes in its dimensions within one week.

These changes at T120 can be explained by the material's characteristics, as it allows longer storage time than conventional alginates ${ }^{3,4,16}$. For IA, this decrease in TD was observed from T24 onwards. In HY5 and JP, changes in TD demonstrate an increasing contraction of materials, which is more significant at T72 and T120 (Table 2), with larger discrepancies at $\mathrm{T} 120$. In contrast to previous studies ${ }^{11,12}$ with different methodologies, this material did not suffer dimensional deformities for a period of five days. The changes observed in the present study may denote shrinkage of alginate molds when they are stored for many hours, as a result of water $\operatorname{loss}^{12}$ and changes due to the influences of storage temperatures ${ }^{3}$.

When the vertical distance was evaluated, there was a significant difference in IA and JP at T120 (Table 2), presenting the lowest values, in agreement with Torassian et al. ${ }^{4}$, who found that traditional alginates suffer greater dimensional distortion as from 72 hours, as they are less resistant to the action of time ${ }^{14}$. At T72 (JP) and T120, IA and JP also presented the lowest mean values, indicating the possibility of presenting greater distortions over time $\mathrm{e}^{3,4,14}$.

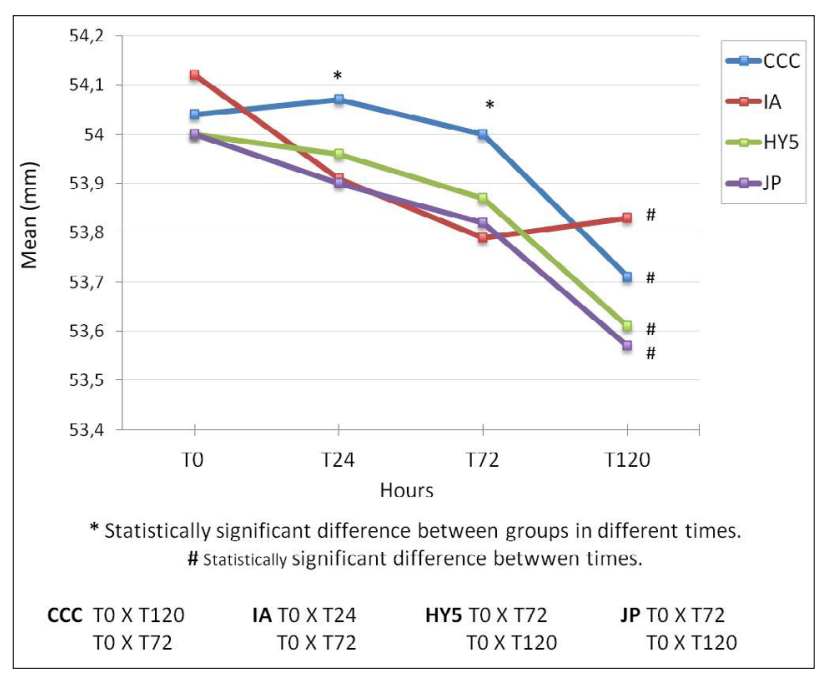

Fig. 3: Transverse distance interaction graph

The percentage change in material dimensions at T0 and T120 (Table 3), obtained from the molding of the upper arch standard typodont, which served as the gold standard in this study, shows a slight, non-significant difference in measurements between materials. Although significant differences were found between some measurements, differences less than or equal to $0.5 \mathrm{~mm}$ are considered clinically insignificant ${ }^{17}$, and only differences greater than or equal to $1.5 \mathrm{~mm}$ are considered clinically significant ${ }^{15}$. According to the American Board of Orthodontics Objective Grading System (ABO OGS), vertical, transverse and anteroposterior discrepancies greater than $0.5 \mathrm{~mm}$ are considered significant ${ }^{18}$. In this study, the differences ranged from $0.2 \mathrm{~mm}$ to $0.6 \mathrm{~mm}$ for measurements and are therefore considered clinically acceptable without compromising treatment planning and control.

Based on the present results it can be concluded that the dimensional accuracy of the molds produced is dependent on the time and material used. Molding materials are not dimensionally stable when evaluated within 120 hours of molding. The most acceptable alginate material with the least distortion when analyzed for up to 120 hours was Cavex Color Change, while the material that suffered the most significant distortions at the time established in this study was Jeltrate Plus. 


\begin{tabular}{|c|c|c|c|c|c|}
\hline & Typodont & CCC & IA & HY5 & JP \\
\hline \multicolumn{6}{|c|}{ TO } \\
\hline \multicolumn{6}{|c|}{ Anteroposterior Distance } \\
\hline Mean & 40.81 & 40.67 & 40.7 & 40.77 & 40.8 \\
\hline Difference & & -0.14 & -0.11 & -0.04 & -0.01 \\
\hline$\%$ & & $-0.34 \%$ & $-0.26 \%$ & $-0.09 \%$ & $-0.02 \%$ \\
\hline \multicolumn{6}{|c|}{ Transverse distance } \\
\hline Mean & 54.05 & 54.03 & 54.12 & 53.99 & 53.99 \\
\hline Difference & & -0.02 & 0.07 & -0.06 & -0.06 \\
\hline$\%$ & & $-0.03 \%$ & $0.12 \%$ & $-0.11 \%$ & $-0.11 \%$ \\
\hline \multicolumn{6}{|c|}{ Vertical Distance } \\
\hline Mean & 11.25 & 11.08 & 11.22 & 11.2 & 11.16 \\
\hline Difference & & -0.17 & -0.03 & -0.05 & -0.09 \\
\hline$\%$ & & $-1.5 \%$ & $-0.26 \%$ & $-0.44 \%$ & $-0.8 \%$ \\
\hline \multicolumn{6}{|c|}{ T120 } \\
\hline \multicolumn{6}{|c|}{ Anteroposterior Distance } \\
\hline Mean & 40.81 & 40.50 & 40.38 & 40.66 & 40.28 \\
\hline Difference & & -0.302 & -0.43 & -0.15 & -0.53 \\
\hline$\%$ & & $-0.7 \%$ & $-1.05 \%$ & $-0.36 \%$ & $-1.2 \%$ \\
\hline \multicolumn{6}{|c|}{ Transverse distance } \\
\hline Mean & 54.05 & 53.70 & 53.82 & 53.61 & 53.56 \\
\hline Difference & & -0.35 & -0.23 & -0.44 & -0.49 \\
\hline$\%$ & & $-0.64 \%$ & $-0.42 \%$ & $-0.81 \%$ & $-0.90 \%$ \\
\hline \multicolumn{6}{|c|}{ Vertical Distance } \\
\hline Mean & 11.25 & 11.07 & 10.91 & 11.09 & 10.86 \\
\hline Difference & & -0.18 & -0.34 & -0.16 & -0.39 \\
\hline$\%$ & & $-1.6 \%$ & $-3.02 \%$ & $-1.42 \%$ & $-3.46 \%$ \\
\hline
\end{tabular}

\section{FUNDING}

This study was financed in part by the Coordenação de Aperfeiçoamento de Pessoal de Nível Superior (CAPES), Brazil

\section{CORRESPONDENCE}

Dra. Thais Maria Freire Fernandes.

Universidade Pitágoras Unopar - UNOPAR

Al Ipe Rosa 956. Zip code:88055782. Londrina, PR,

Brasil.

thaismaria@hotmail.com

their effect on the dimensional accuracy and surface quality of irreversible hydrocolloid impression materials and gypsum casts. Dent Mater 2002;18:103-110.

4. Torassian G, Kau CH, English JD, Powers J, Bussa HI, Marie Salas-Lopez A, Corbett JA. Digital models vs plaster models using alginate and alginate substitute materials. Angle Orthod 2010;80:474-481.

5. Correia GD, Habib FA, Vogel CJ. Tooth-size discrepancy: a comparison between manual and digital methods. Dental Press J Orthod 2014;19:107-113.

6. Moreira DD, Gribel BF, Torres GDR, Vasconcelos KF, Freitas DQ, Ambrosano GMB. Reliability of measurements

3. Taylor RL, Wright PS, Maryan C. Disinfection procedures: 
on virtual models obtained from scanning of impressions and conventional plaster models. Braz J Oral Sci 2014;13:297302.

7. Gimenez B, Ozcan M, Martinez-Rus F, Pradies G. Accuracy of a digital impression system based on parallel confocal laser technology for implants with consideration of operator experience and implant angulation and depth. Int $\mathbf{J}$ Oral Maxillofac Implants 2014;29:853-62.

8. Nedelcu R, Olsson P, Nystrom I, Ryden J, Thor A. Accuracy and precision of 3 intraoral scanners and accuracy of conventional impressions: A novel in vivo analysis method. J Dent 2018;69:110-118.

9. Imbery TA, Nehring J, Janus C, Moon PC. Accuracy and dimensional stability of extended-pour and conventional alginate impression materials. J Am Dent Assoc 2010;141:32-39.

10. Nassar U, Aziz T, Flores-Mir C. Dimensional stability of irreversible hydrocolloid impression materials as a function of pouring time: a systematic review. J Prosthet Dent 2011;106:126-133.

11. Guiraldo RD, Borsato TT, Berger SB, Lopes MB, Gonini A, Jr., Sinhoreti MA. Surface detail reproduction and dimensional accuracy of stone models: influence of disinfectant solutions and alginate impression materials. Braz Dent J 2012;23:417-421.

12. Guiraldo RD, Moreti AF, Martinelli J, Berger SB, Meneghel LL, Caixeta RV, Sinhoreti MA. Influence of alginate impression materials and storage time on surface detail reproduction and dimensional accuracy of stone models. Acta Odontol Latinoam 2015;28:156-161.

13. Slaviero T, Fernandes TM, Oltramari-Navarro PV, de Castro AC, Conti F, Poleti ML, de Almeida MR. Dimensional changes of dental arches produced by fixed and removable palatal cribs: A prospective, randomized, controlled study. Angle Orthod 2017;87:215-222.

14. Todd JA, Oesterle LJ, Newman SM, Shellhart WC. Dimensional changes of extended-pour alginate impression materials. Am J Orthod Dentofacial Orthop 2013;143:S55-63.

15. Tomassetti JJ, Taloumis LJ, Denny JM, Fischer JR, Jr. A comparison of 3 computerized Bolton tooth-size analyses with a commonly used method. Angle Orthod 2001;71:351357.

16. Alcan T, Ceylanoglu C, Baysal B. The relationship between digital model accuracy and time-dependent deformation of alginate impressions. Angle Orthod 2009;79:30-36.

17. Leifert MF, Leifert MM, Efstratiadis SS, Cangialosi TJ. Comparison of space analysis evaluations with digital models and plaster dental casts. Am J Orthod Dentofacial Orthop 2009;136:16 e1-4; discussion 16.

18. Casko JS, Vaden JL, Kokich VG, Damone J, James RD, Cangialosi TJ, Riolo ML, Owens SE, Jr., Bills ED. Objective grading system for dental casts and panoramic radiographs. American Board of Orthodontics. Am J Orthod Dentofacial Orthop 1998;114:589-599. 